Research Article

\title{
Stability Assessment of High and Steep Cutting Rock Slopes with the SSPC Method
}

\author{
Hongliang Tao, ${ }^{1}$ Guangli $\mathrm{Xu},{ }^{1}$ Jingwen Meng, ${ }^{2}$ Ronghe $\mathrm{Ma}^{3}$ and Jiaxing Dong ${ }^{3}{ }^{3}$ \\ ${ }^{1}$ Faculty of Engineering, China University of Geosciences, Wuhan, Hubei 430074, China \\ ${ }^{2}$ Wuhan City Colledge, Wuhan, Hubei 430083, China \\ ${ }^{3}$ Faculty of Electric Power Engineering, Kunming University of Science and Technology, Kunming, Yunnan 650500, China
}

Correspondence should be addressed to Jiaxing Dong; dong1986@kust.edu.cn

Received 7 August 2020; Revised 27 January 2021; Accepted 7 April 2021; Published 20 April 2021

Academic Editor: Luis Neves

Copyright (c) 2021 Hongliang Tao et al. This is an open access article distributed under the Creative Commons Attribution License, which permits unrestricted use, distribution, and reproduction in any medium, provided the original work is properly cited.

\begin{abstract}
The stability of high rock slopes has become a key engineering geological problem in the construction of important projects in mountainous areas. The original slope stability probability classification (SSPC) system, presented by Hack, has made obvious progress and been widely used in rock slope stability analysis. However, the selection and determination of some evaluation indexes in the original SSPC method are usually subjective, such as intact rock strength and weathering degree. In this study, the SSPC method based on geological data obtained in the prospecting tunnels was presented and applied. According to the field survey and exploration of the prospecting tunnels, the weathering degree of the slope rock mass was evaluated. The empirical equation for the maximum stable height of the slope was applied to the slope stability evaluation in the presented SSPC method. Then, the slope stability probability of numerous cutting slopes in the sandstone unit was evaluated using the presented system. Results of the Geostudio software based on the limited equilibrium analysis of the investigated slopes were compared with the results obtained by the SSPC method. The results indicate that the SSPC method is a useful tool for the stability prediction of high and steep rock slopes.
\end{abstract}

\section{Introduction}

The geomorphology in southwest China changes rapidly over short distances; in this region, large-scale projects such as hydropower stations were constructed, with complex geological conditions [1-3]. In recent years, the heights of cutting rock slopes can be as high as $300-500 \mathrm{~m}$. For instance, the maximum cutting slope height at the Dagangshan project located in the Dadu River is $530 \mathrm{~m}$, and the maximum cutting slope height at the Xiaowan project located in the Lancang River is $700 \mathrm{~m} \mathrm{[4].} \mathrm{Cutting} \mathrm{slopes} \mathrm{are} \mathrm{prone} \mathrm{to}$ fail due to the disturbance on original geometry and strength [5], and assessing the stability of these rock slopes is an important and difficult task, due to ensure slope safety in period of construction and running.

Slope stability is affected by numerous factors, such as geological conditions, rock mass mechanical parameters, joint parameters, slope geometry, groundwater condition, and excavation methods. At present, rock mass quality assessment, kinematical, analytical, and numerical analyses are the common methods in rock slope stability assessments [6]. However, the estimation of the parameters needed for the abovementioned methods is always challenging due to the heterogeneity of jointed slope masses [7, 8]. Since 1970, many rock mass classification systems that consider many affecting factors, such as the slope geometry, presence of water or water pressures, weathering effects, and excavation methods, have been proposed or modified and applied in the quantitative stability prediction of rock engineering [9-13]. The existing rock mass classification systems are becoming increasingly popular and are used in research on slopes worldwide as an accurate and useful tool for the rock slope stability assessment. In fact, shortcomings exist in most of the mentioned classification systems; for instance, failure modes of the slopes are always not taken into account, and only single-point data are used, but the slopes always have 
large-scale and complex geological conditions. In addition, slope rock mass and exposure rock mass are always not distinctly differentiated in the existing approach [14]. To overcome the limitations previously, Hack (1998) [15] presented a new rock slope stability assessment approach (SSPC, slope stability probability classification), which has been used worldwide, especially in the research of road slopes in Spain [16], New Zealand, India [17], and Turkey $[5,6,14]$ with good results. As a matter of fact, the method is generally suitable for slopes with a height of less than or equal to $45 \mathrm{~m}$. Moreover, discontinuity property survey, weathering degree, and intact rock strength estimation involve high subjectivity and arbitrariness [14, 17, 18]. For these reasons, the SSPC method is rarely used in the high and steep cutting rock slopes [19].

In this study, key points of the SSPC method are introduced. Then, discontinuity surveys were carried out and data were collected and analyzed at four different prospecting tunnels, and discontinuity properties were obtained and input for the SSPC assessment system; stability of six proposed cutting slopes of the supported project is evaluated using the SSPC method.

\section{Project Background}

2.1. Study Area. The supported hydropower project is located upstream of the Dadu River, Sichuan Province, China, which flows through a valley with $\mathrm{V}$ shape. The reservoir has a normal pool level (NPL) of $2600 \mathrm{~m}$, and the river's natural water level was approximately $2597 \mathrm{~m}$. The basic seismic intensity of this area is VII degrees, indicating a relatively stable area. Slopes in this area were mainly in the metamorphic sandstone unit with upper Triassic and Jurassic bonobo groups. Rock fall phenomena and rock failure (sliding, toppling, and wedge failure seen in Figure 1) commonly occurred at natural slope in this region. In this paper, stability of six proposed cutting rock slopes seen in Figure 2 are studied, including tunnel-face slope (no. 1), intake slope (no. 2), the abutment slope (no. 3), slope of the toe board (no. 4), back-slope of the powerhouse (no. 5), and slope of the powerhouse in the left bank (no. 6) of the Dadu River. In Figure 2, four prospecting tunnels (PD09, PD01, PD07, and PD20) were arranged to find out the geological conditions of the abovementioned slopes. Specifically, discontinuity and rock mass properties, weathering degree, and other related parameters can be obtained by surveys and tests in the prospecting tunnels.

2.2. Discontinuity Properties. The discontinuity properties of the sandstone unit along the study area were determined by means of sample windows, scan lines performed at 5 locations, and other data that were collected by discontinuity statistics exposed in the 4 prospecting tunnels (PD09, PD01, PD07, and PD20, seen in Figure 2) distributed in the dam site. Accordingly, parameters of discontinuity such as the spacing, persistence, roughness, infill condition, and weathering degree were obtained with the suggestions of the International Society for Rock Mechanics (ISRM 2007) [20].
A total of 1276 discontinuities were collected and described, and the main joint sets are shown in Table 1, and a contour plot with Dips software [21] is presented in Figure 3.

Discontinuities develop in the studied slopes, collected in the corresponding prospecting tunnels, and natural exposures were divided into statistical and geological dominant joints based on the field survey and statistical analysis, as shown in Table 2.

Roughness and waviness parameters are of great importance for the stability of discontinuity-controlled failures. An increasing roughness profile of a discontinuity results in a substantial rise in the discontinuity shear strength. The sandstone unit in the study area commonly presents straight and rough discontinuity surfaces. In addition, the roughness of the same discontinuities can be classified as slightly curved $\left(i=2-4^{\circ}\right)$ in large-scale roughness profiles and undulating (amplitude roughness $>2-3 \mathrm{~mm}$ ) in small-scale roughness profiles with respect to the SSPC system. Commonly, no infill material in the discontinuities can be observed in sandstone, whereas surface staining can be observed. In addition, no karst phenomenon can be observed.

\section{The SSPC System and Its Application}

The original SSPC system was presented by Hack (1998) [15] for probabilistic stability assessments of rock slopes, and a related detailed description can be found in some literature $[14,16]$. In this paper, only key points and the steps of stability assessment are introduced.

3.1. Key Points of the SSPC. The SSPC method encompasses a three-step evaluation of the slope stability probability, accordingly identifying three different rock masses (ERM, exposure rock mass; RRM, reference rock mass; SRM, slope rock mass) during evaluation [16].

(a) ERM: exposed rock mass, which is directly observed on the exposure site of a natural or an old engineering slope

(b) RRM: reference rock mass, which is the theoretical and imaginary fresh rock mass, undistributed due to the excavation

(c) SRM: slope rock mass, which is the existing or proposed new slope to be cut (see Figure 4)

(d) Two types of slope failure modes (orientation independent and orientation dependent) and the corresponding stability probability estimation methods are considered, with clear and simple needed-data collecting procedure

Figure 5 is the schematic diagram of the SSPC method; in the SSPC system, the slope stability probability can be evaluated on the basis of parameters obtained from the investigated exposure rock mass, such as the intact rock strength (IRS), discontinuity spacing (SPA), and condition of the discontinuities (CD). Obviously, the parameters obtained on the outcrop are significantly affected by weathering or excavation disturbances. The parameters of the ERM with different weathering and excavation 


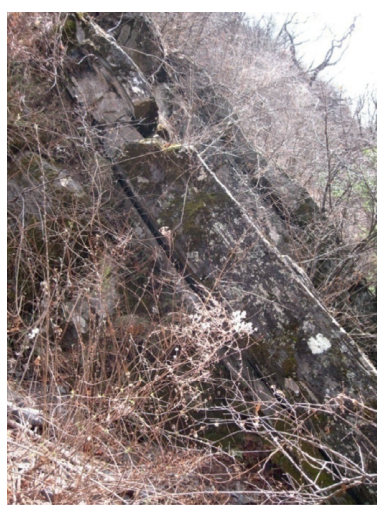

(a)

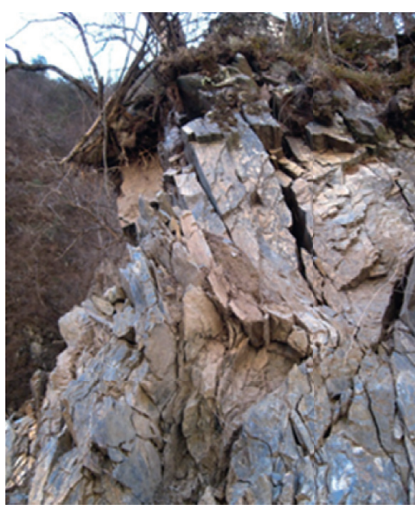

(b)

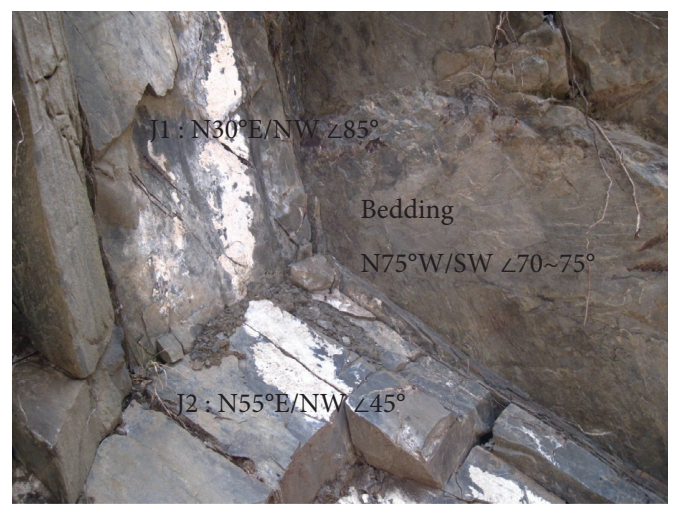

(c)

FIgURE 1: Failure of the natural slopes investigated: (a) sliding, (b) toppling, and (c) wedge failure.

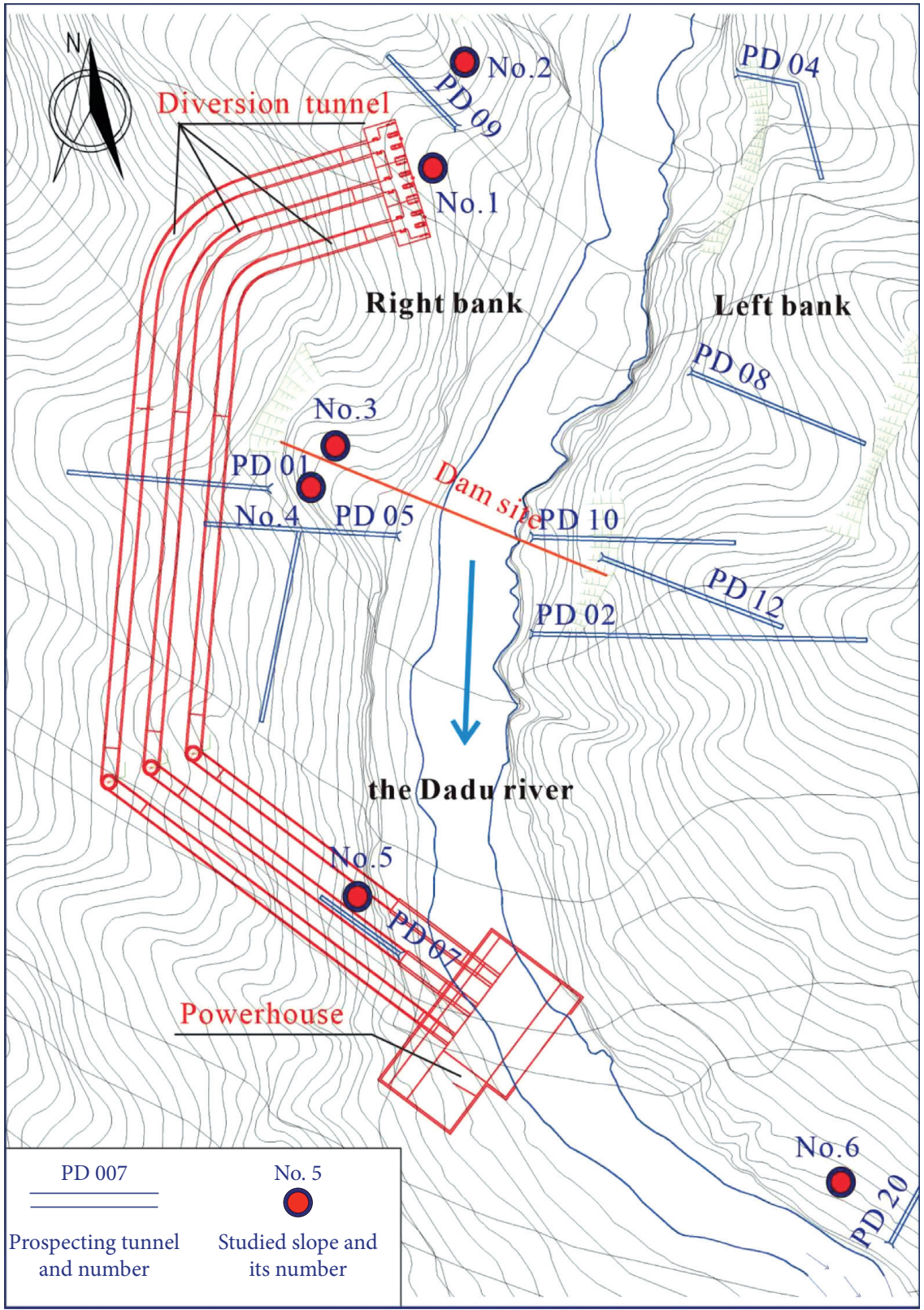

Figure 2: Distribution of the prospecting tunnels in the dam site. 
TABLE 1: Characteristics of the surveyed discontinuity sets in the study area.

\begin{tabular}{lcccc}
\hline Discontinuity & $\begin{array}{c}\text { Dip direction } \\
\left({ }^{\circ}\right)\end{array}$ & $\begin{array}{c}\text { Dip } \\
\left({ }^{\circ}\right)\end{array}$ & $\begin{array}{c}\text { Trace length } \\
(\mathrm{m})\end{array}$ & $\begin{array}{c}\text { Spacing } \\
(\mathrm{m})\end{array}$ \\
\hline 1 & 318 & 66 & $<2$ & $0.1-0.3$ \\
2 & 201 & 62 & - & $0.3-1$ \\
3 & 104 & 34 & $3-5$ & $0.2-0.6$ \\
4 & 28 & 49 & $3-5$ & $0.1-0.3$ \\
\hline
\end{tabular}

disturbance degrees in the same geotechnical unit can be converted to the RRM parameters [16]. The SRM stability is determined from the RRM with the adjustment of the parameters of SRM.

The shear strength parameters of the rock mass including internal friction angle $\phi_{\text {mass }}$ and cohesion $\mathrm{Coh}_{\text {mass }}$ are used to assess the slope stability together with the height of the investigated slope $\left(\mathrm{H}_{\text {slope }}\right)$ [22]. In case the dip of slope $\operatorname{dip}_{\text {slope }}$ is bigger than the internal friction angle $\phi_{\text {mass }}$, the maximum height of a stable slope $\left(H_{\max }\right)$ can be determined by some empirical equations. The orientationindependent stability probability can be assessed using the parameters of $H_{\text {max }}, H_{\text {slope }}, \phi_{\text {mass }}$, and dip slope In addition, the probability of orientation-dependent stability can also be assessed according to the judgment graphs of the SSPC methods.

3.2. Calculation of the Shear Strength Parameters of the RRM. Rock mass shear strength calculation is an important step in SSPC system; when calculation is carried out, parameters such as the intact rock strength (IRS), discontinuity spacing (SPA), roughness, infill, and karst are considered together. The IRS obtained in the laboratory or by the in situ test is divided by the weathering degree factor (WE) for calculating the reference rock intact rock strength (RIRS, see equation (1)). IRS is originally estimated using hammer blows and figure pressure; in this study, laboratory tests were performed, and the results show that intact rock strength of the fresh sandstone ranges from $136 \mathrm{MPa}$ to $274 \mathrm{MPa}$, with an average value of $206 \mathrm{MPa}$. In addition, the slightly weathered sandstone has an average value of $148 \mathrm{MPa}$ [23].

$$
\mathrm{RIRS}=\frac{\mathrm{IRS}}{\mathrm{WE}}
$$

The RSPA (discontinuity spacing of RRM) is determined considering three discontinuity sets that reveal minimum spacing values under the condition of more than three discontinuity sets revealed in the investigated rock mass. Consequently, factors 1,2 , and 3 are obtained using the graph presented in Figure 6. Then, SPA is calculated by equation (2), and the RSPA is calculated by equation (3), considering the factors of the weathering degree (WE) and method of excavation (ME). Referring to $[15,16]$, values of the $\mathrm{WE}$ and $\mathrm{ME}$ can be determined. In this paper, the weathering degree is divided according to the total joint number in a $5 \mathrm{~m}$ section of the prospecting tunnel, which is shown in Table 3.

$$
\begin{aligned}
\mathrm{SPA} & =(\text { Factor } 1) \times(\text { Factor } 2) \times(\text { Factor } 3), \\
\mathrm{RSPA} & =\frac{\mathrm{SPA}}{(\mathrm{WE} \times \mathrm{ME})} .
\end{aligned}
$$

TC, as the condition factor of a discontinuity, is calculated by equation (3). Here, $\mathrm{Rl}$ is a the large-scale roughness, Rs is the small-scale roughness, and Im and $\mathrm{Ka}$ are the factors of infill and karst, respectively. Considering weathering degree correction, TC of the reference rock mass named RTC is defined by equation (5).

$$
\begin{aligned}
\mathrm{TC} & =R l \times R s \times \operatorname{Im} \times K a, \\
\mathrm{RTC} & =\frac{\mathrm{TC}}{\left(1.452-1.22 \times e^{-W E}\right)^{0.5}} .
\end{aligned}
$$

In the SSPC system, the weighted discontinuity condition CD is calculated by equation (5). Here, DS represents the discontinuity spacing. Similarly, the reference discontinuity condition (RCD) is calculated considering the weathering degree factor in Equation (7).

$$
\begin{aligned}
\mathrm{CD} & =\frac{\left(T C_{1} / D S_{1}\right)+\left(T C_{2} / D S_{2}\right)+\left(T C_{3} / D S_{3}\right)}{\left(1 / D S_{1}\right)+\left(1 / D S_{2}\right)+\left(1 / D S_{3}\right)}, \\
\mathrm{RCD} & =\frac{\mathrm{CD}}{\mathrm{WE}} .
\end{aligned}
$$

The friction angle $\left(\phi_{R M}\right)$ and cohesion $\left(C_{R M}\right)$ of a rock mass are calculated by equations (8) and (9). Here, RIRS is the intact rock strength, RSPA is the spacing, and RCD is the condition of discontinuities of the reference rock mass.

$$
\begin{aligned}
& \phi_{\mathrm{RM}}=(\mathrm{RIRS} \times 0.2417) \times(\mathrm{RSPA} \times 52.12) \times(\mathrm{RCD} \times 5.779), \\
& C_{\mathrm{RM}}=(\mathrm{RIRS} \times 94.27) \times(\mathrm{RSPA} \times 28629) \times(\mathrm{RCD} \times 3593) .
\end{aligned}
$$

3.3. Orientation-Dependent Stability Assessment of the SRM. As mentioned above, in the SSPC system, both orientation-dependent and orientation-independent conditions are considered in the slope rock mass stability evaluation. As the term suggests, failures controlled by discontinuities such as planar sliding and toppling usually occur in the orientation-dependent stability analysis, while failures occur irrespective of a certain sliding surface in orientation-independent stability analysis. However, the probability of wedge failures cannot be evaluated in the SSPC system.

For the former type of stability assessment, factors such as the discontinuity condition (STC) and the apparent angle of the discontinuity dip in the direction of the slope dip (AP) are considered for evaluating the stability probability. The AP is obtained based on equation (10), where $\alpha_{s}$ represents the direction, $\alpha_{j}$ represents the dip direction of the discontinuity, and $\beta_{j}$ represents the discontinuity dip. 


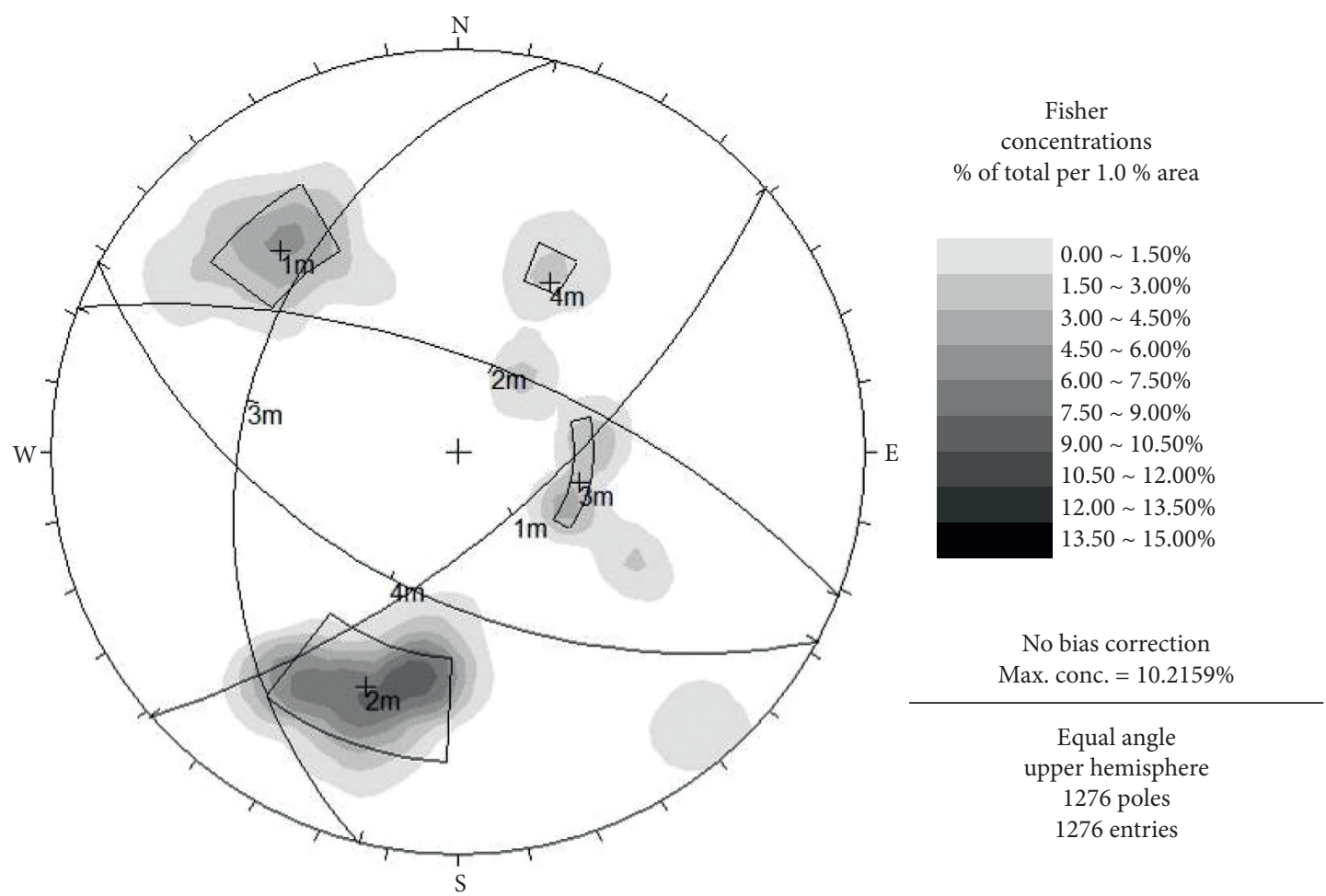

Figure 3: Contour plot of the field-surveyed discontinuity in the study area.

TABLE 2: Characteristics of the main discontinuity sets in the surveyed slopes.

\begin{tabular}{|c|c|c|c|c|c|c|c|c|}
\hline \multirow{2}{*}{ Slope } & \multirow{2}{*}{ Joint } & \multicolumn{3}{|c|}{ Statistical dominant discontinuity } & \multicolumn{3}{|c|}{ Geological dominant discontinuity } & \multirow{2}{*}{$\begin{array}{c}\text { Note } \\
\text { Prospecting tunnel }\end{array}$} \\
\hline & & Dip direction $\left({ }^{\circ}\right)$ & Dip $\left({ }^{\circ}\right)$ & Spacing $(\mathrm{m})$ & Dip direction $\left({ }^{\circ}\right)$ & Dip $\left(^{\circ}\right)$ & Spacing $(\mathrm{m})$ & \\
\hline \multirow{3}{*}{1} & $\mathrm{~B}_{1}$ & 217 & 70 & $0.2-0.5$ & 190 & 70 & $0.2-0.5$ & \multirow{6}{*}{ PD09 } \\
\hline & $J_{1}$ & 113 & 32 & $0.1-0.3$ & 75 & 45 & $0.1-0.3$ & \\
\hline & $J_{2}$ & 138 & 83 & $0.1-0.3$ & 305 & 55 & $0.1-0.3$ & \\
\hline \multirow{3}{*}{2} & $\mathrm{~B}_{1}$ & 217 & 70 & $0.2-0.5$ & 215 & 75 & $0.3-0.6$ & \\
\hline & $J_{1}$ & 113 & 32 & $0.1-0.3$ & 130 & 15 & $0.2-0.4$ & \\
\hline & $\mathrm{J}_{2}$ & 138 & 83 & $0.1-0.3$ & 130 & 80 & $0.2-0.4$ & \\
\hline \multirow{3}{*}{3} & $\mathrm{~B}_{1}$ & 194 & 66 & $0.1-0.5$ & 190 & 60 & $0.1-0.5$ & \multirow{6}{*}{ PD01 } \\
\hline & $J_{1}$ & 122 & 54 & $0.2-0.6$ & 120 & 55 & $0.2-0.6$ & \\
\hline & $J_{2}$ & 318 & 69 & $0.2-0.6$ & 335 & 60 & $0.2-0.6$ & \\
\hline \multirow{3}{*}{4} & $\mathrm{~B}_{1}$ & 194 & 66 & $0.1-0.5$ & 185 & 65 & $0.2-0.6$ & \\
\hline & $J_{1}$ & 122 & 54 & $0.2-0.6$ & 125 & 60 & $0.3-0.7$ & \\
\hline & $J_{2}$ & 318 & 69 & $0.2-0.6$ & 330 & 65 & $0.3-0.7$ & \\
\hline \multirow{3}{*}{5} & $\mathrm{~B}_{1}$ & 205 & 68 & $0.1-0.4$ & 205 & 70 & $0.1-0.4$ & \multirow{3}{*}{ PD07 } \\
\hline & $J_{1}$ & 78 & 38 & $0.1-0.4$ & 70 & 25 & $0.1-0.3$ & \\
\hline & $J_{2}$ & 327 & 64 & $0.2-0.4$ & 315 & 60 & $0.3-0.4$ & \\
\hline \multirow{3}{*}{6} & $\mathrm{~B}_{1}$ & 195 & 75 & $0.2-0.5$ & 200 & 50 & $0.1-0.4$ & \multirow{3}{*}{ PD20 } \\
\hline & $J_{1}$ & 325 & 45 & $0.1-0.3$ & 140 & 85 & $0.2-0.4$ & \\
\hline & $\mathrm{J}_{2}$ & 300 & 85 & $0.2-0.6$ & 35 & 45 & $0.3-0.7$ & \\
\hline
\end{tabular}

Meanwhile, the discontinuity condition of the slope (STC) is determined by equation (11).

$$
\begin{aligned}
\mathrm{AP} & =\arctan \left[\cos \left(\alpha_{s}-\alpha_{j}\right) \tan \beta_{j}\right], \\
\mathrm{STC} & =\mathrm{RTC} \times\left(1.452-1.220 \times \mathrm{e}^{-S W E}\right)^{0.5} .
\end{aligned}
$$

For sliding failure, a relationship graph (see Figure $7(\mathrm{a})$ ) between the STC and AP is employed to assess the occurrence probability of the slope. Furthermore, a relationship graph of the STC, AP, and dipslope (see Figure 7(b)) is employed to evaluate the occurrence probability of the slope for toppling failure. In this paper, the probability results and the necessary parameters for 


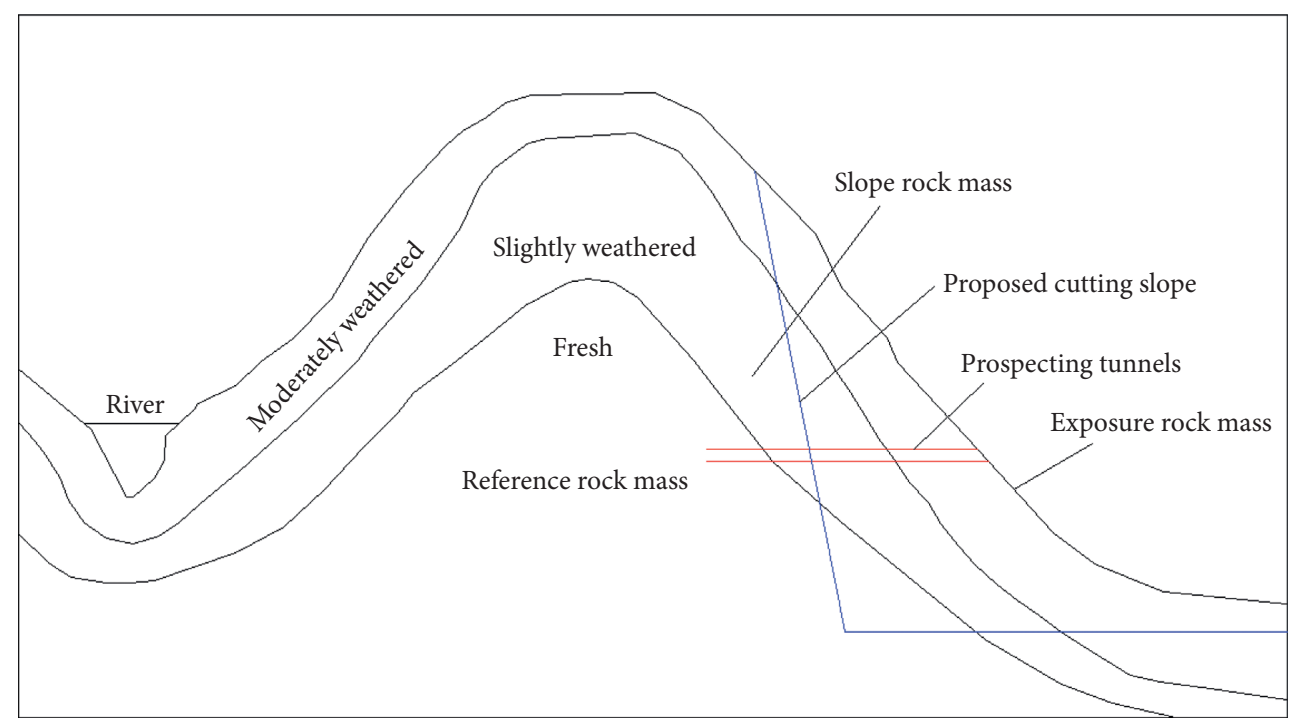

FIGURE 4: Sketch of exposures in rock masses of various degrees of weathering and different types of excavation indicating the concept of the reference rock mass.

Exposure-specific parameters

1. Method of excavation

2. Degree of weathering
Exposure rock mass (ERM):

Parameters significant for slope stability assessment:

A. Material properties:

1. Intact rock strength (IRS)

2. Susceptibility to weathering (WE)

B. Discontinuities:

3. Orientation of discontinuity (dip/dip direction)

4. Spacing between discontinuity sets $(\mathrm{m})$

C. Discontinuity properties:

5. Roughness large scale (Rl) and small scale (Rs)

6. Infilling materials (Im)

7. Karst (Ka) (may not be present)
Slope-specific parameters

1. Method of excavation to be used

2. Expected degree of weathering at the end of engineering life time of slope

Slope geometry calculation: 1. Orientation of the slope

(dip and strike of the slope)

2. Height of the slope $\left(\mathrm{H}_{\text {slope }}\right)$

3. Maximum slope height $\left(\mathrm{H}_{\max }\right)$

\section{Factors used to establish the}

Reference rock mass (RRM):

Same parameters which have been collected for:

Exposure rock mass to be used to calculate parameters of

reference rock mass unit for slope stability assessment

1. Angle of friction ( $f_{\text {mass }}$ )

2. Cohesion (Cohmass)

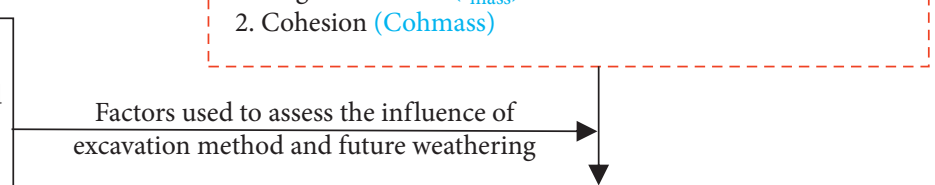

Slope rock mass (SRM):

Slope rock mass parameters significant for slope stability: 1. Material properties: strength, susceptibility to weathering

2. Discontinuities: orientation sets (spacing) or single

3. Discontinuity properties: roughness, infill, karst

Figure 5: Flowchart of the SSPC method (modified after Canal A and Akin M, 2016). 


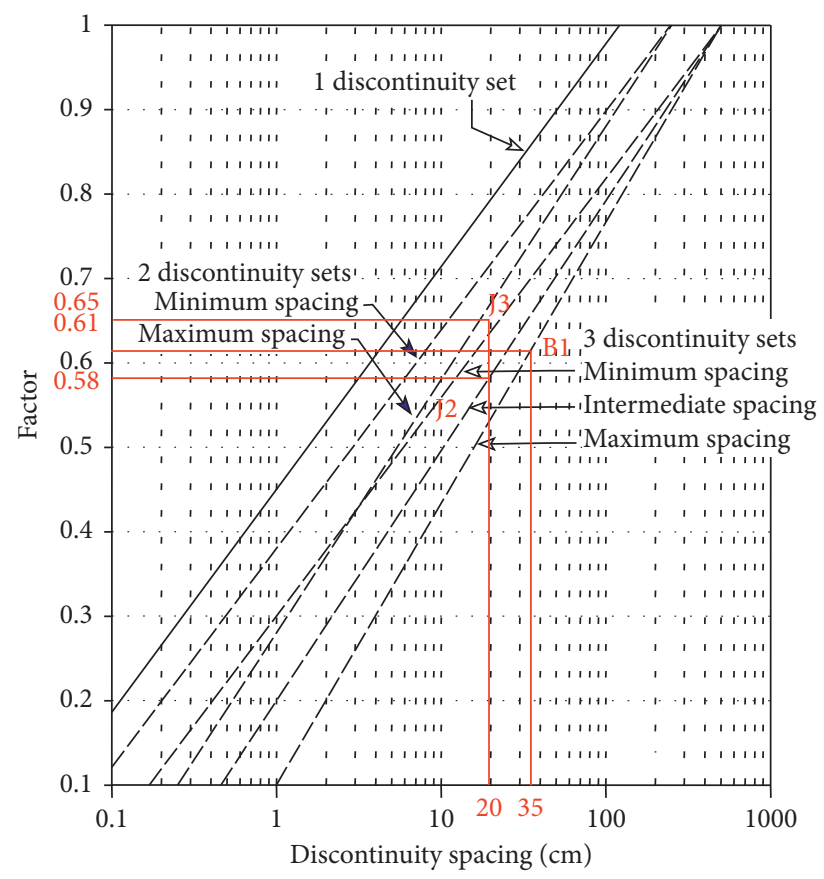

FIGURE 6: Factor determination graph in accordance with the discontinuity spacing [16].

TABLE 3: Weathering degree and its classification.

\begin{tabular}{lcc}
\hline Degree & Joint number in a $5 \mathrm{~m}$ section & Value of WE \\
\hline Complete & $50-60$ & 0.35 \\
High & $40-50$ & 0.62 \\
Moderate-high & $30-40$ & 0.77 \\
Moderate-slight & $20-30$ & 0.92 \\
Slight & $10-20$ & 0.95 \\
Fresh & $0-10$ & 1.00 \\
\hline
\end{tabular}

probability calculations in the study area are summarized in Table 4.

3.4. Orientation-Independent Stability Assessment of the SRM. Parameters needed in the calculation of stability of slope rock mass such as SIRS, SSPA, and SCD are determined as equation (12), in which the RRM values are corrected by the the weathering degree (SWE) and method of excavation (SME) for existing natural/excavated slopes.

Accordingly, the friction angle and cohesion of the slope mass are defined by equation (13). Obviously, an orientation-independent stability problem cannot occur under the condition of the dip slope $\leq \phi_{\mathrm{SRM}}$ of the investigated slopes. However, the stability condition is evaluated on the basis of the maximum slope height $\left(H_{\max }\right)[14,16]$. The orientationindependent slope stability probability can be easily determined by the chart seen in Figure 8 . However, the assessment method of the maximum slope height $\left(H_{\max }\right)$ was modified by Li et al. [19] if the height of slope is larger than $45 \mathrm{~m}$. In this study, we assessed the $H_{\max }$ using the modified formulation $\mathrm{H}_{\text {max-Huang. The necessary parameters and }}$ probability calculations in the study area are summarized in
Table 5. A final assessment of the slopes (see Table 5) was performed by choosing the largest failure probability determined via the two analyses.

$$
\begin{aligned}
& \left\{\begin{array}{l}
\text { SIRS }=\text { RIRS } \times \text { SWE } \\
\text { SSPA }=\text { RSPA } \times \text { SWE } \times \text { SME } \\
\text { SCD }=\text { RCD } \times \text { SWE }
\end{array}\right. \\
& \left\{\begin{array}{l}
\phi_{\text {SRM }}=(\mathrm{SIRS} \times 0.2417) \times(\mathrm{SSPA} \times 52.12) \times(\mathrm{SCD} \times 5.779), \\
\mathrm{C}_{\mathrm{SRM}}=(\mathrm{SIRS} \times 94.27) \times(\mathrm{SSPA} \times 28629) \times(\mathrm{SCD} \times 3593),
\end{array}\right. \\
& \left\{\begin{array}{l}
H_{\text {max }-\mathrm{SSPC}}=\frac{\left[1.6 \times 10^{4} \times C_{\mathrm{SRM}} \times \sin \left(\operatorname{dip}_{\text {slope }}\right) \times \cos \left(\phi_{\mathrm{SRM}}\right)\right]}{1-\cos \left(\operatorname{dip}_{\text {slope }}-\phi_{\mathrm{SRM}}\right)} \\
H_{\text {max }- \text { Huang }}=\left(0.00651+0.00037 m_{i}^{1.5}\right) \times\left(\frac{\sigma_{c i}}{\gamma}\right) e^{\mathrm{GSI}\left(-0.0003 m_{i}+0.0483\right)} .
\end{array}\right.
\end{aligned}
$$

\section{Discussion}

Results seen in Tables 4 and 5 show that the calculated slopes were defined as stable. In addition, we also calculated the slope stability by the Geostudio software according to the step of the building model, parameters inputting, and calculating. Figure 9 is the typical simulation model of slope 2; compared with the outcome through the Geostudio software (Table 6), the results prove the validity and convenience of the SSPC methods introduced above. In addition, it is important selecting the suitable discontinuities for assessment of the stability probability in the SSPC method. In this study, 


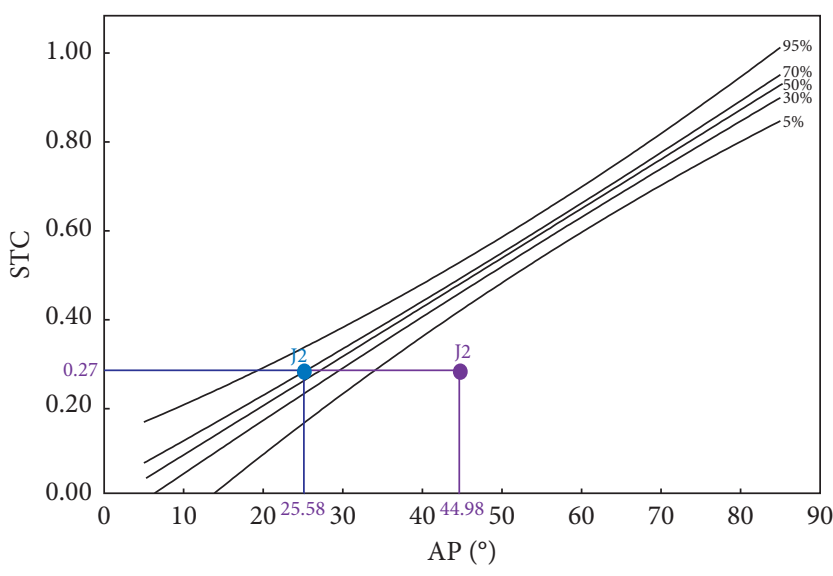

(a)

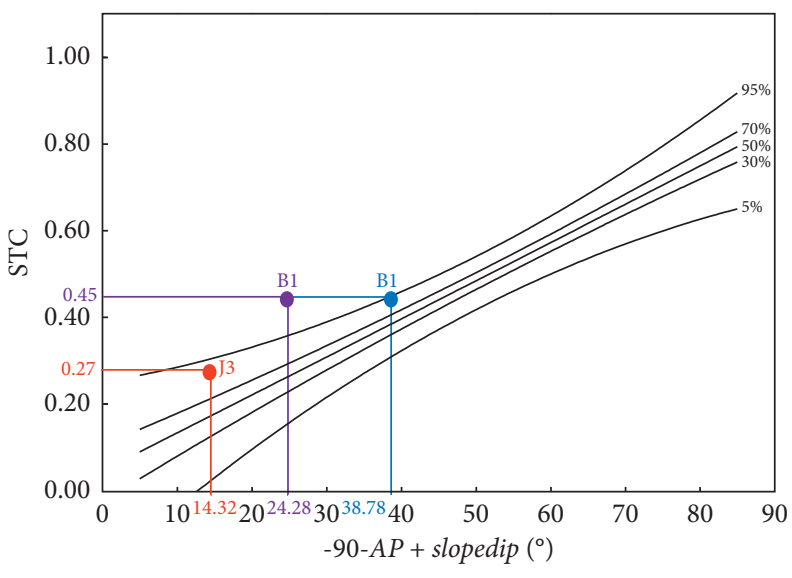

(b)

FIGURE 7: Flowchart of the SSPC methods determined by sliding and toppling (slope 1). (a) Sliding. (b) Toppling.

TABLE 4: Orientation-dependent stability probabilities of discontinuities at the typical investigated slopes.

\begin{tabular}{|c|c|c|c|c|c|c|}
\hline Slope & Discontinuity & STC & $\mathrm{AP}$ & Sliding probability & Toppling probability & Slope stability probability \\
\hline \multirow{3}{*}{1} & $\mathrm{~B}_{1}$ & 0.45 & -65.78 & $100 \%$ & $95 \%$ & \multirow{3}{*}{$70 \%$} \\
\hline & $J_{2}$ & 0.27 & 25.58 & $70 \%$ & $100 \%$ & \\
\hline & $J_{3}$ & 0.27 & 73.80 & $100 \%$ & $100 \%$ & \\
\hline \multirow{3}{*}{2} & $\mathrm{~B}_{1}$ & 0.45 & 58.23 & $100 \%$ & $100 \%$ & \multirow{3}{*}{$95 \%$} \\
\hline & $J_{1}$ & 0.27 & 21.88 & $95 \%$ & $100 \%$ & \\
\hline & $J_{2}$ & 0.27 & 82.28 & $100 \%$ & $100 \%$ & \\
\hline \multirow{3}{*}{3} & $\mathrm{~B}_{1}$ & 0.61 & -42.41 & $100 \%$ & $>95 \%$ & \multirow{3}{*}{$95 \%$} \\
\hline & $J_{1}$ & 0.65 & 45.65 & $>95 \%$ & $100 \%$ & \\
\hline & $J_{2}$ & 0.42 & -54.08 & $100 \%$ & $95 \%$ & \\
\hline \multirow{3}{*}{4} & $\mathrm{~B}_{1}$ & 0.61 & -42.41 & $100 \%$ & $>95 \%$ & \multirow{3}{*}{$95 \%$} \\
\hline & $J_{1}$ & 0.65 & 45.65 & $>95 \%$ & $100 \%$ & \\
\hline & $J_{2}$ & 0.42 & -54.08 & $100 \%$ & $95 \%$ & \\
\hline \multirow{3}{*}{5} & $\mathrm{~B}_{1}$ & 0.76 & -60.26 & $100 \%$ & $>95 \%$ & \multirow{3}{*}{$>95 \%$} \\
\hline & $J_{1}$ & 0.65 & 37.73 & $>95 \%$ & $100 \%$ & \\
\hline & $J_{2}$ & 0.65 & -24.76 & $100 \%$ & $>95 \%$ & \\
\hline \multirow{3}{*}{6} & $\mathrm{~B}_{1}$ & 0.76 & 67.37 & $>70 \%$ & $100 \%$ & \multirow{3}{*}{$>70 \%$} \\
\hline & $J_{1}$ & 0.65 & 9.85 & $>95 \%$ & $100 \%$ & \\
\hline & $J_{2}$ & 0.65 & 81.33 & $100 \%$ & $100 \%$ & \\
\hline
\end{tabular}

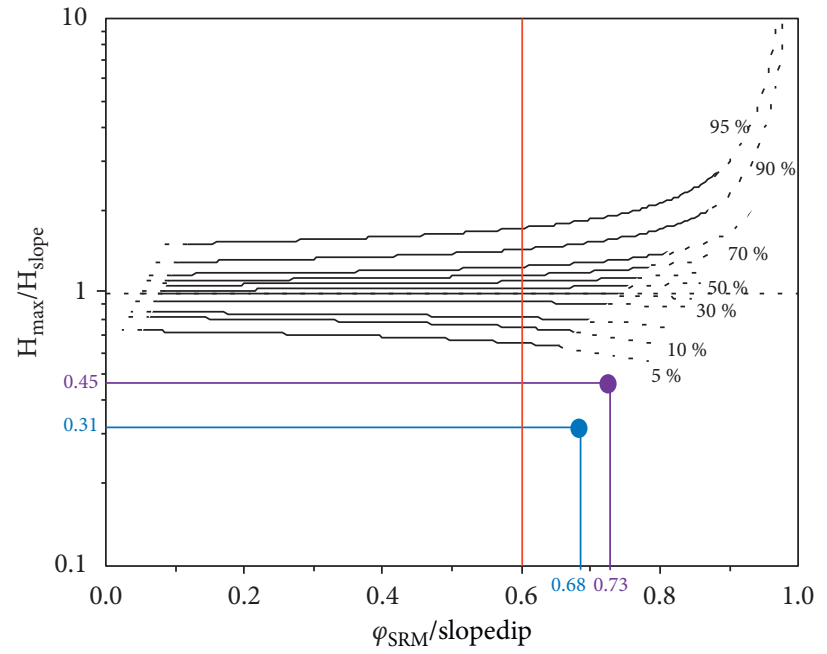

FIGURE 8: Flowchart of the SSPC methods determined by orientation-independent failure (slope 1). 
TABLe 5: Summary of the orientation-independent stability probability at the investigated slopes.

\begin{tabular}{|c|c|c|c|c|c|c|c|c|}
\hline Slope & $\mathrm{H}_{\text {slope }}(\mathrm{m})$ & $\operatorname{dip}_{\text {slope }}\left({ }^{\circ}\right)$ & $\mathrm{C}_{\mathrm{SRM}}(\mathrm{MPa})$ & $\phi_{\mathrm{SRM}}\left({ }^{\circ}\right)$ & $H_{\max }(\mathrm{m})$ & $H_{\max } / \mathrm{H}_{\text {slope }}$ & $\phi_{\mathrm{SRM}} / \mathrm{dip}_{\text {slope }}$ & Slope stability probability \\
\hline 1 & 105 & 63 & 0.584 & 37.84 & 1322.56 & 12.60 & 0.60 & $>95 \%$ \\
\hline 2 & 105 & 63 & 1.525 & 53.71 & 5044.85 & 48.05 & 0.85 & $>95 \%$ \\
\hline 3 & 180 & 73 & 1.030 & 39.27 & 2010.88 & 11.17 & 0.54 & $>95 \%$ \\
\hline 4 & 180 & 73 & 1.385 & 45.02 & 3045.16 & 16.92 & 0.62 & $>95 \%$ \\
\hline 5 & 90 & 73 & 0.648 & 30.89 & 1322.56 & 14.70 & 0.42 & $>95 \%$ \\
\hline 6 & 65 & 73 & 0.882 & 41.43 & 1849.98 & 28.46 & 0.57 & $>95 \%$ \\
\hline
\end{tabular}

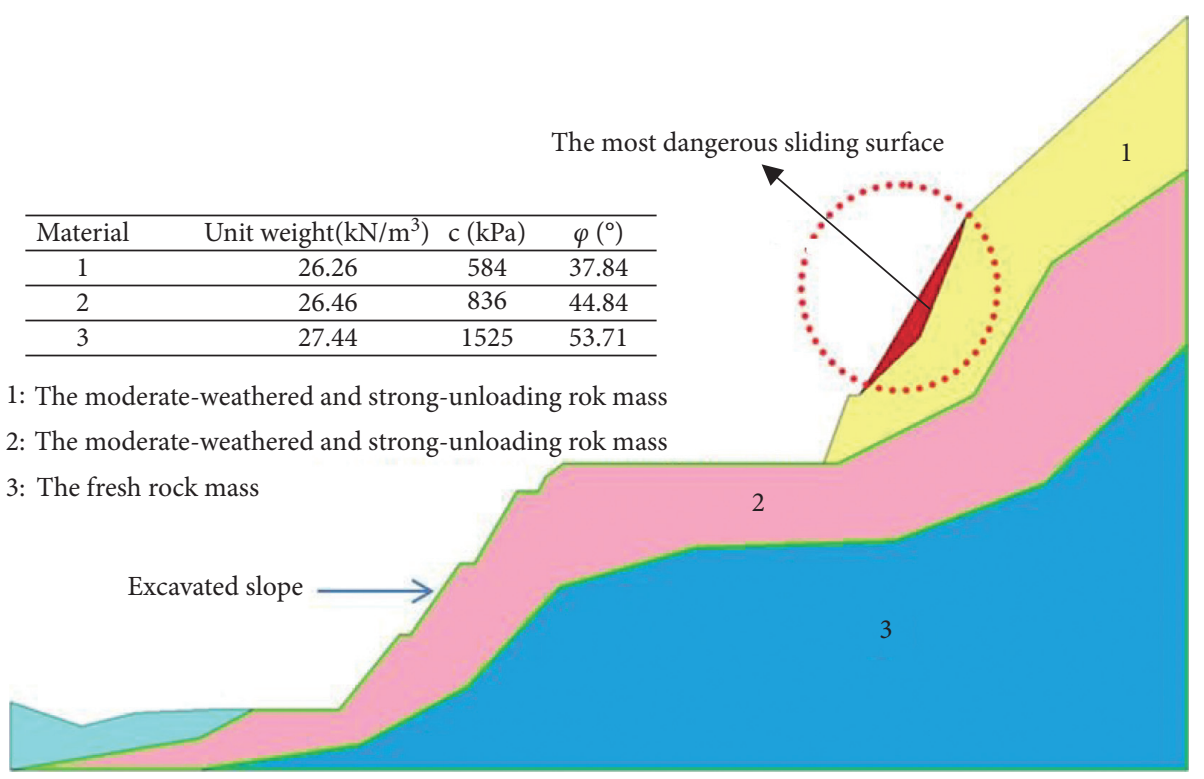

Figure 9: Typical simulation model of slope 2 using the Geostudio software.

TABLE 6: Summary of the stability assessment result using the Geostudio software and the SSPC method.

\begin{tabular}{cccccc}
\hline Slope & \multicolumn{2}{c}{$\begin{array}{c}\text { Safety factor values under different } \\
\text { conditions } \\
\text { Normal }\end{array}$} & Stability assessment result by Geostudio & Stability probability by the SSPC method \\
\hline 1 & 1.325 & 1.198 & Earthquake & Stable & $70 \%$ \\
2 & 1.188 & 1.301 & 1.377 & Stable & $95 \%$ \\
3 & 1.476 & 1.266 & 1.376 & Stable & $95 \%$ \\
4 & 1.408 & 1.285 & 1.293 & Stable & $95 \%$ \\
5 & 1.480 & 1.279 & 1.290 & Stable & $>95 \%$ \\
6 & 1.282 & 1.405 & 1.135 & Stable & $>70 \%$ \\
\hline
\end{tabular}

statistical dominant discontinuities obtained in the prospecting tunnels and natural outcrops were selected, but not the geological dominant discontinuities only obtained and determined by the natural outcrops.

\section{Conclusions}

In this study, the SSPC method based on geological data obtained in the prospecting tunnels was presented, and the slope stability probability of very high $(50-300 \mathrm{~m})$ and steep $\left(60^{\circ}-75^{\circ}\right)$ cutting slopes in the sandstone unit was investigated using the proposed system. The following conclusions can be drawn.
Firstly, three sets of joints were presented in each studied slope. To overcome bias, laboratory data of the uniaxial compressive strength and rock mass strength parameters can be used for SSPC directly.

Secondly, statistically dominant discontinuities obtained in the prospecting tunnels and natural outcrops were suitable for the SSPC method, but not the geological dominant discontinuities only obtained and determined by the natural outcrops.

Finally, the formula of the critical slope height is optimized and applied to the stability evaluation, and the SSPC method based on geological data obtained in the prospecting tunnels can be accurately applied to the stability evaluation of high and steep rock slopes. 


\section{Data Availability}

The data used to support the findings of this study are included within the article.

\section{Conflicts of Interest}

The authors declare that they have no conflicts of interest.

\section{Acknowledgments}

This study was sponsored by the Program of the Yunnan Natural Science Foundation (no. 2015FD008) and Talent Development Program of Kunming University of Science and Technology (no. KKSY201504022). The authors thank Zhenluo Shen for his contribution to the resolution improvement of the figures in this article.

\section{References}

[1] R. Huang, "Main characteristics of high rock slopes in southwestern China and their dynamic evolution," Advances in Earth Science, vol. 20, no. 3, pp. 292-297, 2005.

[2] S. W. Song, X. M. Feng, B. Y. Xiang et al., "Research on key technologies for high and steep rock slopes of hydropower engineering in Southwest China," Chinese Journal of Rock Mechanics and Engineering, vol. 30, no. 1, pp. 1-22, 2011.

[3] J. X. Dong, G. L. Xu, and S. S. Zhang, A New Proposed Rockfall Hazard Rating System for Surrounding Slope in Large Hydropower Project, pp. 1327-1340, EJGE, New York, NY, USA, 2014.

[4] X. Y. Jing, Y. Wu, Y. Zeng et al., "Application of two dimensional limit equilibrium method in high slope engineering," Design of Hydroelectric Power Station, vol. 36, no. 4, pp. 1-3, 2020.

[5] T. Ersoz and T. Topal, "Assessment of rock slope stability with the effects of weathering and excavation by comparing deterministic methods and slope stability probability classification (SSPC)," Environmental Earth Sciences, vol. 77, no. 547, pp. 1-18, 2018.

[6] A. Canal and M. Akin, "Assessment of rock slope stability by probabilistic-based Slope Stability Probability Classification method along highway cut slopes in Adilcevaz-Bitlis (Turkey)," Journal of Mountain Science, vol. 13, no. 11, pp. 1893-1909, 2016.

[7] Z. C. Tang, Q. Z. Zhang, and J. Peng, "Effect of thermal treatment on the basic friction angle of rock joint," Rock Mechanics and Rock Engineering, vol. 53, no. 4, pp. 1973-1990, 2020.

[8] Z. Tang and Y. Jiao, "Choosing appropriate appraisal to describe peak spatial features of rock joint profiles," International Journal of Geomechanics, vol. 20, no. 4, Article ID 04020021, 2020.

[9] Z. T. Bieniawski, "Engineering classification of jointed rock masses," Journal of the South African Institution of Civil Engineering, vol. 15, no. 12, pp. 343-353, 1973.

[10] Z. Chen, "Recent developments in slope stability analysis," in Proceedings of the 8th International Congress ISRM, pp. 1041-1048, Tokyo, Japan, May 1995.

[11] A. Singh, "Frhi - a system to evaluate and mitigate rockfall hazard in stable rock excavations," J Div Civ Eng Inst Eng (India), vol. 85, pp. 62-75, 2004.
[12] Y. C. Shi, Z. W. Wang, G. R. Wan, Z. Y. Wang, Q. Y. Chen, and S. C. Tang, "Study of mountain highway slope mass rating," Chinese Journal of Rock Mechanics and Engineering, vol. 24, no. 6, pp. 939-944, 2005.

[13] L. Pantelidis, "Rock slope stability assessment through rock mass classification systemsfication systems," International Journal of Rock Mechanics and Mining Sciences, vol. 46, no. 2, pp. 315-325, 2009.

[14] X. Z. Li and Q. Xu, "Application of the SSPC method in the stability assessment of highway rock slopes in the Yunnan province of China," Bulletin of Engineering Geology and the Environment, vol. 75, no. 2, pp. 551-562, 2016.

[15] H. R. G. K. Hack, Slope Stability Probability Classification, SSPCp. 258, 2nd edition, ITC, Enschede, The Netherlands, 1998.

[16] R. Hack, D. Price, and N. Rengers, "A new approach to rock slope stability-a probability classification (SSPC)," Bulletin of Engineering Geology and the Environment, vol. 62, no. 2, pp. 167-184, 2003.

[17] P. Lindsay, J. Anderson, F. Bourke, R. N. Campbell, and L. Clarke, "Predicting slope stability in open pit gold and coal mines," in Proceedings of the New Zealand Minerals and Mining Conference Proceedings, pp. 29-31, Wellington, New Zealand, October 2000.

[18] L. Xiu-zhen, T. Rong-zhi, and G. Yan, "Modification of slope stability probability classification and its application to rock slopes in hydropower engineering regions," Geologia Croatica, vol. 72, pp. 71-80, 2019.

[19] X. Z. Li, J. M. Kong, and S. W. Li, "Stability probability classification method for rock slope in hydropower engineering region," Chinese Journal of Rock Mechanics and Engineering, vol. 30, no. 2, pp. 4025-4032, 2011.

[20] ISRM (International Society for Rock Mechanics), "The complete ISRM suggested methods for rock characterization, testing and monitoring: 1974-2007: suggested methods prepared by the commission on testing methods," International Society for Rock Mechanics, vol. 15, 2007.

[21] Rocscience Inc. (1998) Dips v.5.0-graphical and statistical analysis of orientation data. Available online at: http://www. rocscience.com.

[22] I. Das, S. Sahoo, C. van Westen, A. Stein, and R. Hack, "Landslide susceptibility assessment using logistic regression and its comparison with a rock mass classification system, along a road section in the northern Himalayas (India)," Geomorphology, vol. 114, no. 4, pp. 627-637, 2010.

[23] R.-H. Ma, HSSPC Method and its Application in High and Steep Rock Slope in Hydropower Engineering, Kunming University of Science and Technology, Kunming, China, 2020. 